\title{
Research on Sustainable Development of Resource-Based Cities Based on the DEA Approach: A Case Study of Jiaozuo, China
}

\author{
Li Li, ${ }^{1,2}$ Yalin Lei, ${ }^{1,2}$ Dongyang Pan, ${ }^{3}$ and Chunyan $\mathrm{Si}^{1,2}$ \\ ${ }^{1}$ School of Humanities and Economic Management, China University of Geosciences, Beijing 100083, China \\ ${ }^{2}$ Key Laboratory of Carrying Capacity Assessment for Resource and Environment, Ministry of Land and Resources, \\ Beijing 100083, China \\ ${ }^{3}$ Central University of Finance and Economics, Beijing 100081, China
}

Correspondence should be addressed to Yalin Lei; leiyalin@cugb.edu.cn

Received 4 September 2015; Accepted 27 December 2015

Academic Editor: Aime’ Lay-Ekuakille

Copyright (C) $2016 \mathrm{Li} \mathrm{Li}$ et al. This is an open access article distributed under the Creative Commons Attribution License, which permits unrestricted use, distribution, and reproduction in any medium, provided the original work is properly cited.

\begin{abstract}
Jiaozuo is a typical resource-based city, and its economic transformation has been an example of success in China. However, quantitative evaluation of the city's development has scarcely been performed, and future development is not clear. Because of this, using the relevant data from 1999 to 2013, this paper uses the data envelopment analysis (DEA) model to evaluate development after the transformation of Jiaozuo with the aim of providing a basis for its future developing plan. The results show that DEA was effective in 2000, 2004, 2006, 2010, and 2012, was weakly effective in 1999, 2001, 2002, 2003, and 2013, and was ineffective in 2005, 2007, 2008, 2009, and 2011. By evaluating the development of Jiaozuo, this paper provides policy implications for Jiaozuo's sustainable development, and it may serve as a reference for the sustainable development of China's other resources-based cities.
\end{abstract}

\section{Introduction}

The sustainable development of resource-based cities has an important influence on the development of China's cities. Promoting sustainable development of resources-based cities is an important measure to protect the supply of resources and maintain sustainable and healthy development for the national economy. With the current rise in economic uncertainty and the imbalance of the domestic economy, coordination and sustainability have become important, and the sustainable development of resource-based cities faces severe challenges. It is difficult to accelerate economic development and achieve sustainable development. It is important to change the predicament and realize the importance of the sustainable development of resource-based cities at a national sustainable development strategy. According to statistical data, there are 262 resource-based cities in China, which account for $40 \%$ of the total number of cities [1]. Presently, 67 cities of the 262 resource-based cities are in recession.

In 2002, The 16th Party Congress made the strategic decision to support cities and areas mainly engaged in the exploitation of natural resources in their efforts to develop alternative industries [2]. In 2007, the State Council proposed several ideas to promote the sustainable development of resource-based cities, including a guiding ideology, basic principles, and objectives to promote the sustainable development of resource-based cities [3]. In 2013, the State Council issued a plan for the sustainable development of national resource-based cities, which mentioned that China would have resolved or basically resolved the issues faced by the resource-recession cities left behind by history and significantly enhanced the capability of sustainable development and essentially completed the transformation by 2020 . China would have mostly achieved the coordination between resources and socioeconomic development in resource-based cities [1].

Jiaozuo, a city in the Henan province, is a typical resourcebased city which used to be known as the "coal city" and where the added value from the resource industry at one time accounted for more than $80 \%$ of the added value from all industries. However, due to the depletion of coal and the rise of the single industry structure, the average annual economic 
growth rate of Jiaozuo was only 3.5\% in the "9th five-year" period.

Jiaozuo's GDP fell by $16 \%$ and financial revenue fell by $24 \%$ in 1999, and the entire city was in urgent need of transformation. In March 2008, with the approval of the State Council, Jiaozuo, as a representative resource-exhausted city in the central region, was chosen as one of the first 12 resource-exhausted cities, bringing opportunities for the sustainable development to the city [4]. In just a few years, the development of the entire city of Jiaozuo has seen a sharp economic upturn. However, contradictions in the industrial structural still exist. The proportion of industries that are tertiary industry is $20 \%$ below the national; the multifaceted development of the industrial system has not yet come to fruition in Jiaozuo. Based on this background, this paper evaluates the sustainable development of Jiaozuo to provide for a reference for the sustainable development of other resource-based cities.

\section{Literature Review}

2.1. The Development of Resource-Based Cities. International research on resource-based cities began in the 1930s, with the pioneering efforts of Innis, a Canadian scholar [5]. Subsequently, in the 1960s, oil gradually replaced coal, and coal resource-based cities fell into recession. With this, the transformation and sustainable development of resourcebased cities became the focus of study among many scholars. Foreign studies on resource-based cities were mainly conducted in developed countries, such as the United States [68], Germany [9, 10], Canada [11], Australia [12], and other mining countries. Successful examples were found mainly in the Ruhr industrial region in Germany, the Welsh region in the United Kingdom, Lorraine in France, and Kitakyushu in Japan. Studies were mainly based on the principles of philosophy, sociology $[13,14]$, and demography $[15,16]$, as well as transformation and sustainable development $[17,18]$.

After the reform and opening up, China began to conduct research on resource-based cities. Li [19] conducted an indepth analysis of the development of coal resource-based cities in 1978 and was considered to be the pioneer of research on resource-based cities. Subsequently, with the problems of resource-based cities continuously emerging and intensifying, theoretical research on the transformation of resource-based cities and sustainable development gradually took off and generally concentrates on the following aspects.

First, researchers studied the adjustment, optimization, and transformation of the economic structure (industrial structure) of a particular resource-based city or a region, including Wu and Ye [20], Liu [21], Dong et al. [22], and Song and Man [23]. These studies assessed the difficulties in the industrial structure transformation of resource-based cities and discussed countermeasures based on the characteristics of the resource-based cities.

Second, researchers studied the transformation and sustainable development of resource-based cities. Based on cases of circular economies in resource-based cities, $\mathrm{Li}$ and Zhang [24] established a circular economy evaluation index system for resource-based cities using resources, economy, environment, and society to evaluate the main factors that affect the circular economy of resource-based cities. Taking Karamay, a city in Xingjiang, as an example, Zhang and Gao [25] quantitatively evaluated the sustainable development capacity of Karamay with AHP methods. The study indicated that Karamay was at a weak stage of sustainable development and that its sustainable development capacity was relatively weak. $\mathrm{Li}$ et al. [26] found deficiencies in the process of policy implementation and provided recommendations to improve transition performance and sustainable development in resource-based cities. Using environmental production technology and a Malmquist resource performance index (MRPI), Dong et al. [27] conducted tests on the transformation performance of 21 resource-based cities in China. The results indicated that MRPI did not follow the same trends as three Chinese regions that were experiencing economic growth. Hong and Kai [28] used small industrial mining cities in Shanxi province to propose relevant strategies for sustainable development, primarily analyzing their functional transformation and various problems during their sustainable development efforts.

For resource-based cities, $\mathrm{Xu}$ [30] built a three-tiered indication system and put forward an appraisal model, which combined AHP and statistics to evaluate Jiaozuo's sustainable development. Feng [31] studied the development of tourism in Jiaozuo and indicated that Jiaozuo tourism was at the development stage according to lifecycle model theory. Chen et al. [32] recognized the potential of coal as a resource that should be utilized. Moreover, the circulation utilization of coal should be performed, and the aluminum industry and traveling industry should be greatly developed. Based on the ecological carrying capacity theory and analytic hierarchy process, Chang et al. [33] calculated an ecological resilience index, ecological carrying index, and ecological pressing index, and they emphasized air pollution as a factor to analyze and evaluate the ecological carrying capacity of Jiaozuo. The results showed that Jiaozuo had relatively stable, high, and high-pressure carrying capacity.

\subsection{Sustainable Development Evaluation. As there are differ-} ences in the sustainable development of resource-based cities and other cities, this paper reviews the evaluation indexes and methods used in comprehensive sustainable development research.

Foreign research on evaluation indexes in sustainable development was conducted earlier and more comprehensively. However, as foreign resource-based cities and towns began to experience transformation in the 1960s and 1970s, the indexes of sustainable development were not perfect. Thus, foreign research on evaluation indexes in sustainable development is rare, generally due to three factors. First, from the perspective of ecology and economics, Moffatt [34] deemed that ecological indicators could move towards sustainable development. Rees and Wackernagel [35] recognized that ecological footprints were key to urban sustainability. Second, from the perspective of sociology, several indicators were used, including the Human Development Indicators (HDI), Genuine Progress Indicators (GPI), and Indexes of Sustainable Economic Welfare (ISEW) in United Nations 
TABLE 1: The evaluation index of the sustainable development in Jiaozuo.

\begin{tabular}{|c|c|c|}
\hline \multirow{2}{*}{$\begin{array}{l}\text { Evaluation factor } \\
\text { layer } \\
\text { Input indexes } X\end{array}$} & \multicolumn{2}{|c|}{ Evaluation index layer } \\
\hline & $\begin{array}{r}\text { The } 1 \\
\text { L } \\
\text { A } \\
\text { A }\end{array}$ & $\begin{array}{l}\text { rs at the end of the year (million) } x 1 \\
\text { enditure (ten thousand yuan) } x 2 \\
\text { tment (ten thousand yuan) } x 3 \\
\text { sumption (ten thousand tons) } x 4 \\
\text { sumption (ten thousand Kwh) } x 5\end{array}$ \\
\hline Output indexes $Y$ & $\begin{array}{l}\text { Subindex of society } \\
\text { development } y 2 \\
\text { Subindex of environment } \\
\text { development } y 3\end{array}$ & $\begin{array}{l}\text { Industrial added value (a hundred million yuan) y11 } \\
\text { Gross regional product (a hundred million yuan) y12 } \\
\text { The proportion of secondary industry (\%) y13 } \\
\text { Sustainable income of urban residents (yuan) y14 } \\
\text { Rural net income per capita (yuan) y15 } \\
\text { The population growth rate (\%o) y21 } \\
\text { Public facilities land (hectare) y22 } \\
\text { Urban unemployment rate (\%) y23 } \\
\text { Location investment (ten thousand yuan) y24 } \\
\text { The number of buses owned by urban people per ten } \\
\text { thousand (vehicle) y25 } \\
\text { Total industrial wastewater discharge (ten thousand } \\
\text { tons) y31 } \\
\text { Industrial } \mathrm{SO}_{2} \text { emissions (ton) y32 } \\
\text { Industrial dust emissions (ton) y33 }\end{array}$ \\
\hline
\end{tabular}

TABLE 2: Industry structure in Jiaozuo [29].

\begin{tabular}{cccc}
\hline Year & $\begin{array}{c}\text { Primary } \\
\text { industry }\end{array}$ & $\begin{array}{c}\text { Secondary } \\
\text { industry }\end{array}$ & $\begin{array}{c}\text { Tertiary } \\
\text { industry }\end{array}$ \\
\hline 2000 & 17.2 & 50.6 & 32.2 \\
2001 & 16.3 & 51.3 & 32.4 \\
2002 & 14.8 & 52.6 & 32.6 \\
2003 & 11.6 & 55.5 & 32.9 \\
2004 & 11.5 & 59.7 & 28.8 \\
2005 & 10.1 & 62.5 & 27.4 \\
2006 & 8.9 & 64.2 & 26.9 \\
2007 & 8.5 & 65.8 & 25.7 \\
2008 & 8.1 & 66.9 & 25.0 \\
2009 & 8.0 & 67.3 & 24.7 \\
2010 & 8.1 & 68.6 & 23.3 \\
2011 & 7.8 & 69.7 & 22.5 \\
2012 & 7.9 & 67.5 & 24.6 \\
2013 & 7.8 & 67.4 & 24.8 \\
\hline
\end{tabular}

Development Program (UNDP) [36]. Third, speaking from the perspective of the system, scholars believe that sustainable development is a complex system of "economy, society and environment." Giddings et al. [37] recognized that the economy, the environment, and humans were interconnected and that they depended on each other. Based on the perspective of the economy, society, resources, population, and environment, Li [38], Wu and Cheng [39], and Shi [40] and Xu [41] built an index system model of sustainable development to estimate the sustainable development of resource-based cities.

Regarding the evaluation methods used in comprehensive sustainable development research, different scholars utilize different methods, such as the fuzzy comprehensive evaluation method, analytic hierarchy process, principal component analysis, gray correlation analysis method, and data envelopment analysis (DEA). Ravetz [42] used an integrated assessment (IA) approach to map linkages between environmental, economic, and social factors. Using the fuzzy version of the TOPSIS method, Zavadskas and Antucheviciene [43] assumed that a multicriteria analysis was an appropriate technique to ensure sustainability. Using the data from 1995 to 2000 in Jixi city, Hao and Dai [44] chose entropy to estimate the sustainable development of coal-based cities. The estimation results were in agreement with the actual conditions. W. Li and J. Li [45] utilized the DEA model to compare Shanxi's transformational efficiency. The results showed that the DEA model was both objective and effective. Wen and Li [46] produced a fuzzy DEA model based on credibility measure. The hybrid algorithm combined with fuzzy simulation and genetic algorithm was designed to solve the fuzzy model. Wen et al. [47] carried out some researches to DEA under fuzzy environment. The paper also provided an example to illustrate the fuzzy DEA model and the ranking method. Hajiagha et al. [48] transformed the original DEA model to an equivalent linear parametric programming model, using the notion of $\alpha$-cuts. The paper examined the application of the proposed model in two numerical examples and the results were compared with two current fuzzy DEA models. Liu et al. [49] used a network clustering method to make a research front in DEA during the period from 2000 to 2014. The study also updated the main paths and author statistics of DEA development.

\subsection{Literature Summary}

(1) Based on the research, developed countries had a relatively successful transition experience in the 
TABLE 3: Total variance explained.

\begin{tabular}{|c|c|c|c|c|c|c|}
\hline \multirow{2}{*}{ Component } & \multicolumn{3}{|c|}{ Initial eigenvalues } & \multicolumn{3}{|c|}{ Extraction sums of squared loadings } \\
\hline & Total & $\%$ of variance & Cumulative $\%$ & Total & $\%$ of variance & Cumulative \% \\
\hline 1 & 3.565 & 71.301 & 71.301 & 3.565 & 71.301 & 71.301 \\
\hline 2 & 1.116 & 22.324 & 93.625 & 1.116 & 22.324 & 93.625 \\
\hline 3 & 0.205 & 4.091 & 97.716 & & & \\
\hline 4 & 0.089 & 1.790 & 99.505 & & & \\
\hline 5 & 0.025 & 0.495 & 100.000 & & & \\
\hline
\end{tabular}

Extraction method: principal component analysis.

TABLE 4: Communality.

\begin{tabular}{lcc}
\hline & Initial & Extraction \\
\hline $\begin{array}{l}\text { The number of workers at the end of the } \\
\text { year (million) } x 1\end{array}$ & 1.000 & 0.966 \\
$\begin{array}{l}\text { Local financial expenditure (ten thousand } \\
\text { yuan) } x 2\end{array}$ & 1.000 & 0.884 \\
$\begin{array}{l}\text { Fixed asset investment (ten thousand yuan) } \\
x 3\end{array}$ & 1.000 & 0.949 \\
$\begin{array}{l}\text { Annual water consumption (ten thousand } \\
\text { tons) } x 4\end{array}$ & 1.000 & 0.907 \\
$\begin{array}{l}\text { Annual power consumption (ten thousand } \\
\text { Kwh) } x 5\end{array}$ & 1.000 & 0.975 \\
\hline
\end{tabular}

Extraction method: principal component analysis.

TABle 5: Component matrix ${ }^{\mathrm{a}}$.

\begin{tabular}{lcc}
\hline & \multicolumn{2}{c}{ Component } \\
& 1 & 2 \\
\hline $\begin{array}{l}\text { The number of workers at the end of the } \\
\text { year (million) } x 1\end{array}$ & 0.267 & 0.946 \\
$\begin{array}{l}\text { Local financial expenditure (ten thousand } \\
\text { yuan) } x 2\end{array}$ & 0.918 & 0.203 \\
$\begin{array}{l}\text { Fixed asset investment (ten thousand yuan) } \\
x 3\end{array}$ & 0.970 & 0.093 \\
$\begin{array}{l}\text { Annual water consumption (ten thousand } \\
\text { tons) } x 4\end{array}$ & -0.889 & 0.341 \\
$\begin{array}{l}\text { Annual power consumption (ten thousand } \\
\text { Kwh) } x 5\end{array}$ & 0.959 & -0.236 \\
\hline
\end{tabular}

Extraction method: principal component analysis.

${ }^{a} 2$ components extracted.

twentieth century, while it was still difficult to explore the sustainable development of most resource-based cities in China. Presently, the new contradiction in resource-based cities is emerging, and the pressures of sustainable development are great. In some areas, the intensity of development is too high, the comprehensive utilization of resources is too low, and the ecological environment has been seriously destroyed. Although Jiaozuo has left the plight of development, it still faces the challenges of achieving development harmony between the economy, society, and environment. Therefore, it is necessary to explore the challenges to sustainable development in resourcebased cities in the 13th five-year period.

(2) Although domestic studies on sustainable development evaluation indexes have been conducted, it is not so much that quantitative research on Jiaozuo is lacking; rather, it is a lack of objective and effective evaluation. Compared to other evaluation methods, DEA has the following advantages over other methods. (1) It is superior in the evaluation of effectiveness, especially for the multi-input and multioutput systems. (2) It is not necessary to treat the raw data as nondimensional and set weights, which is very objective. DEA analysis is simple and clear, and with the projection analysis, the non-DEA effective decision-making unit can be changed into a DEA effective decision-making unit, which can improve the non-DEA direction for decision makers. Considering the advantages of DEA, the paper uses DEA to assess the sustainable development of Jiaozuo, which complements existing research.

\section{Model and Data}

3.1. DEA. DEA was proposed by Charnes, Cooper, and Rhodes in 1978, and it was used to assess the relative effectiveness of departments. The first model by Charnes, Cooper, and Rhodes is named $\mathrm{C}^{2} \mathrm{R}$. This model is used to study multi-inputs, and especially multioutputs [50]. Banker et al. put forward the $\mathrm{BC}^{2}$ model [51]. Then, Charnes et al. developed the $\mathrm{C}^{2} \mathrm{GS}^{2}$ model [52] and Färe and Grosskopf proposed the FG model [53]. Subsequently, $C^{2} \mathrm{~W}$ [54] and $\mathrm{C}^{2} \mathrm{WH}$ [55] were also proposed. As $\mathrm{C}^{2} \mathrm{R}$ cannot assess the pure technical efficiency of the DMU, the paper uses $\mathrm{BC}^{2}$ to evaluate the sustainable development of Jiaozuo.

Suppose that there are $n$ decision-making units (DMUs) and these $n$ units are comparable. Each department or unit has $m$ types of input (the resource consumption of the unit) and $s$ types of output (the output after resource consumption of the unit).

Where, for $j$ th, $x_{i j}$ is the input of $i$ th, $x_{i j}>0, y_{r j}$ is the output of $r$ th, $y_{r j}>0$, making

$$
\begin{aligned}
& X_{j}=\left(x_{1 j}, x_{2 j}, \ldots, x_{m j}\right)^{T}, \\
& Y_{j}=\left(y_{1 j}, y_{2 j}, \ldots, y_{s j}\right)^{T}, \\
& \quad j=1,2, \ldots, n
\end{aligned}
$$


TABLE 6: Total variance explained.

\begin{tabular}{|c|c|c|c|c|c|c|}
\hline \multirow{2}{*}{ Component } & \multicolumn{3}{|c|}{ Initial eigenvalues } & \multicolumn{3}{|c|}{ Extraction sums of squared loadings } \\
\hline & Total & $\%$ of variance & Total & $\%$ of variance & Total & $\%$ of variance \\
\hline 1 & 7.805 & 60.041 & 60.041 & 7.805 & 60.041 & 60.041 \\
\hline 2 & 2.000 & 15.385 & 75.426 & 2.000 & 15.385 & 75.426 \\
\hline 3 & 1.210 & 9.309 & 84.734 & 1.210 & 9.309 & 84.734 \\
\hline 4 & 0.893 & 6.872 & 91.606 & & & \\
\hline 5 & 0.620 & 4.767 & 96.373 & & & \\
\hline 6 & 0.340 & 2.617 & 98.990 & & & \\
\hline 7 & 0.074 & 0.573 & 99.562 & & & \\
\hline 8 & 0.037 & 0.282 & 99.844 & & & \\
\hline 9 & 0.014 & 0.104 & 99.948 & & & \\
\hline 10 & 0.004 & 0.028 & 99.976 & & & \\
\hline 11 & 0.003 & 0.020 & 99.996 & & & \\
\hline 12 & 0.000 & 0.004 & 100.000 & & & \\
\hline 13 & $2.046 E-006$ & $1.574 E-005$ & 100.000 & & & \\
\hline
\end{tabular}

Extraction method: principal component analysis.

TABLE 7: Communality.

\begin{tabular}{|c|c|c|}
\hline & Initial & Extraction \\
\hline $\begin{array}{l}\text { Industrial added value (a hundred million } \\
\text { yuan) } y 11\end{array}$ & 1.000 & 0.985 \\
\hline $\begin{array}{l}\text { Gross regional product (a hundred million } \\
\text { yuan) } y 12\end{array}$ & 1.000 & 0.996 \\
\hline The proportion of secondary industry (\%) y13 & 1.000 & 0.962 \\
\hline $\begin{array}{l}\text { Sustainable income of urban residents (yuan) } \\
y 14\end{array}$ & 1.000 & 0.993 \\
\hline Rural net income per capita (yuan) $y 15$ & 1.000 & 0.991 \\
\hline The population growth rate (\%o) y21 & 1.000 & 0.810 \\
\hline Public facilities land (hectare) $y 22$ & 1.000 & 0.960 \\
\hline Urban unemployment rate (\%) y23 & 1.000 & 0.600 \\
\hline Education investment (ten thousand yuan) y24 & 1.000 & 0.907 \\
\hline $\begin{array}{l}\text { The number of buses owned by urban people } \\
\text { per ten thousand (vehicles) y } 25\end{array}$ & 1.000 & 0.611 \\
\hline $\begin{array}{l}\text { Total industrial wastewater discharge (ten } \\
\text { thousand tons) } y 31\end{array}$ & 1.000 & 0.515 \\
\hline Industrial $\mathrm{SO}_{2}$ emissions (ton) y32 & 1.000 & 0.810 \\
\hline Industrial dust emissions (tons) y33 & 1.000 & 0.876 \\
\hline
\end{tabular}

Extraction method: principal component analysis.

Thus, $T_{\mathrm{BC}^{2}}=\left\{(x, y) \mid x \geq \sum_{j=1}^{n} \lambda_{j} x_{j}, \sum_{j=1}^{n} \lambda_{j}=1, j=\right.$ $1,2, \ldots, n\}$.

The paper constructs the $\mathrm{BC}^{2}$ model as follows:

$$
\begin{array}{ll}
\min & \theta=V_{D} \\
\text { s.t. } & \sum_{j=1}^{n} X_{j} \lambda_{j} \leq \theta X_{0} \\
& \sum_{j=1}^{n} Y_{j} \lambda_{j} \geq Y_{0} \\
& \sum_{j=1}^{n} \lambda_{j}=1 \\
& \boldsymbol{\omega} \geq 0, \boldsymbol{\mu} \geq 0, \quad j=1, \ldots, n,
\end{array}
$$

$$
\begin{array}{ll}
\max & \left(\boldsymbol{\mu}^{T} Y_{0}+u_{0}\right)=V_{p} \\
\text { s.t. } & \boldsymbol{\omega}^{T} \mathbf{x}_{j}-\boldsymbol{\mu}^{T} \mathbf{y}_{j} \geq 0, \quad j=1, \ldots, n \\
& \boldsymbol{\omega}^{T} \mathbf{x}_{0}=1 \\
& \boldsymbol{\omega} \geq 0, \boldsymbol{\mu} \geq 0
\end{array}
$$

The DEA model is defined as follows. (1) If $\boldsymbol{\omega}_{0}$ and $\boldsymbol{\mu}_{0}$ satisfy $V_{p}=\mu^{T} Y_{0}=1, j_{0}$ can be recognized as weak DEA effectiveness. (2) If $\boldsymbol{\omega}_{0}>0, \boldsymbol{\mu}_{0}>0$, and $V_{p}=\boldsymbol{\mu}^{T} Y_{0}=1$, $j_{0}$ can be recognized as DEA effectiveness. (3) Taking $i>$ 0 at random, $t$ is a certain time point, if $\theta(t-i)<\theta(t)$; thus the system is on the path of sustainable development. If $\theta(t-i)>\theta(t)$, the system is inferior to the path of sustainable development. If $\theta(t-i)=\theta(t)$, the system is somewhat inferior to the path of sustainable development.

3.2. Index System Construction and Data Source. From the sustainable development perspective on resource-based cities, sustainable development is a dynamic process, which is composed of resources, society, economy, environment, and population. The coordinated development among the subsystems should be taken into account in the evaluation of sustainable development. According to the previous studies and the current development of Jiaozuo, this paper constructs the evaluation index of the sustainable development in Jiaozuo in Table 1 as follows. The data from 1999 to 2013 are all from China City Statistical Yearbook [56] and Jiaozuo Yearbook 2000 to 2014 [29].

\section{Results and Discussion}

\subsection{Economic Development in Jiaozuo}

4.1.1. GDP in Jiaozuo. As seen in Figure 1, the growth of GDP in Jiaozuo was very slow in 2000 . However, there was a substantial increase in the growth rate after 2000, especially 
TABLE 8: Component matrix ${ }^{\mathrm{a}}$.

\begin{tabular}{|c|c|c|c|}
\hline & \multicolumn{3}{|c|}{ Component } \\
\hline & 1 & 2 & 3 \\
\hline Industrial added value (a hundred million yuan) $y 11$ & 0.976 & -0.175 & 0.031 \\
\hline Gross regional product (a hundred million yuan) y12 & 0.985 & -0.157 & 0.032 \\
\hline The proportion of secondary industry (\%) y13 & 0.945 & 0.236 & -0.117 \\
\hline Sustainable income of urban residents (yuan) $y 14$ & 0.975 & -0.199 & 0.050 \\
\hline Rural net income per capita (yuan) y15 & 0.956 & -0.268 & 0.070 \\
\hline The population growth rate (\%o) y21 & -0.250 & -0.044 & 0.864 \\
\hline Public facilities land (hectare) y22 & 0.932 & 0.253 & -0.168 \\
\hline Urban unemployment rate (\%) y23 & 0.447 & 0.493 & 0.395 \\
\hline Education investment (ten thousand yuan) y24 & 0.865 & -0.398 & 0.013 \\
\hline The number of buses owned by urban people per ten thousand (vehicles) y 25 & 0.557 & 0.513 & 0.193 \\
\hline Total industrial wastewater discharge (ten thousand tons) y31 & 0.110 & 0.663 & 0.250 \\
\hline Industrial $\mathrm{SO}_{2}$ emissions (ton) $y 32$ & 0.289 & 0.762 & -0.382 \\
\hline Industrial dust emissions (tons) y33 & -0.916 & 0.163 & -0.102 \\
\hline
\end{tabular}

Extraction method: principal component analysis

${ }^{a} 3$ components extracted.

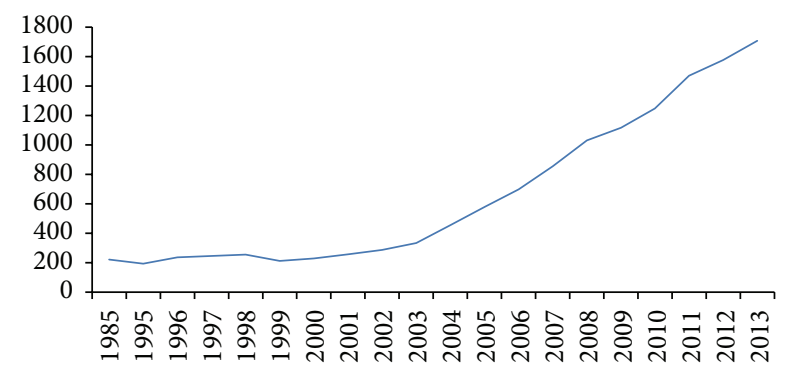

FIGURE 1: GDP in Jiaozuo from 1985 to 2013 (a hundred million yuan) [53].

after 2003, which showed Jiaozuo's economy had progressed after the transformation.

4.1.2. Industrial Structure in Jiaozuo. In Table 2, it can be observed that the proportion of the primary industry has decreased. The proportion of the secondary industry has increased. Although it decreased slightly in 2012 and 2013, it remained high, accounting for more than $67 \%$ of all industries. From Figure 2, in can be seen that the industrial added value accounting for GDP also rose from $32.3 \%$ in 2000 to $63.5 \%$ in 2013 and peaked at $65.8 \%$ in 2011 . Despite an increase in the output value of the tertiary industry, the rate of increase is lower than in the secondary industry; therefore, the proportion made up by the tertiary industry has decreased, with the exception of a slight increase in 2012 and in 2013.

\subsection{Evaluation Analysis of Sustainable Development in Jiaozuo}

4.2.1. Principal Component Analysis (PCA) of the Original Data. A PCA on the original data shows a reduction in

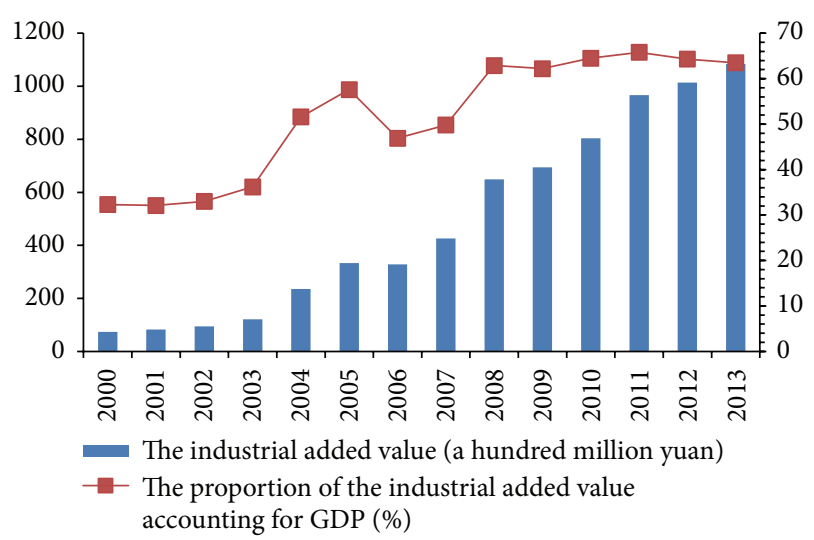

FIgURE 2: The industrial added value and its proportion in GDP in Jiaozuo [29].

the amount of the original data with only a small loss in the amount of information, and this analysis greatly reduces the amount of computation at the same time. In the application, the selection of the principal components is usually based on the variance accumulation percentage of the main components above $80 \%$. The total variance explained, communality, and component matrix of the input indexes are shown in Tables 3, 4, and 5 .

As shown in Tables 3, 4, and 5, the cumulative contribution rate of the first two principal components in the input indexes is $93.625 \%$, which meets the requirements of being above $80 \%$, indicating that only the first and second principal components can represent all input indexes. The characteristic values of the first and second principal components are 3.565 and 1.116, respectively (greater than 1).

Similarly, the total variance explained, communality, and component matrix of the output indexes are shown in Tables 6,7 , and 8 . 
TABLE 9: The comprehensive efficiency analysis of the sustainable development of Jiaozuo.

\begin{tabular}{ccccccc}
\hline Year & $\theta$ & $S_{1}{ }^{-}$ & $S_{2}{ }^{-}$ & $S_{1}{ }^{+}$ & $S_{2}{ }^{+}$ & $S_{3}{ }^{+}$ \\
\hline 1999 & 0.619 & 0.000 & 0.000 & 0.000 & 0.000 & 0.000 \\
2000 & 1.000 & 0.000 & 0.000 & 0.000 & 0.000 & 0.000 \\
2001 & 0.288 & 0.000 & 0.000 & 0.000 & 0.000 & 0.000 \\
2002 & 0.311 & 0.000 & 0.000 & 0.000 & 0.000 & 0.000 \\
2003 & 0.465 & 0.000 & 0.000 & 0.000 & 0.000 & 0.000 \\
2004 & 1.000 & 0.000 & 0.000 & 0.000 & 0.000 & 0.000 \\
2005 & 0.666 & 0.000 & 0.000 & 0.439 & 1.786 & 0.685 \\
2006 & 1.000 & 0.000 & 0.000 & 0.000 & 0.000 & 0.000 \\
2007 & 0.597 & 0.000 & 0.000 & 5.042 & 1.832 & 0.738 \\
2008 & 0.891 & 0.000 & 0.000 & 4.488 & 1.494 & 0.000 \\
2009 & 0.882 & 1.966 & 0.000 & 2.659 & 2.004 & 0.000 \\
2010 & 1.000 & 0.000 & 0.000 & 0.000 & 0.000 & 0.000 \\
2011 & 0.723 & 1.521 & 0.000 & 0.000 & 3.940 & 0.866 \\
2012 & 1.000 & 0.000 & 0.000 & 0.000 & 0.000 & 0.000 \\
2013 & 0.817 & 0.000 & 0.000 & 0.000 & 0.000 & 0.000 \\
\hline
\end{tabular}

As shown in Tables 6,7 , and 8 , the cumulative contribution rate of the first three principal components in the input indexes is $84.734 \%$, which meets the requirements of being above $80 \%$, indicating that the first, second, and third principal components can represent all output indexes. The characteristic values of the first, second, and third principal components are $7.805,2.000$, and 1.210 , respectively (greater than 1).

\subsubsection{DEA Result Analysis}

(1) Sustainable Development Efficiency Evaluation. This analysis uses $Y_{i}^{\prime}=e^{Y_{i}}, X_{i}^{\prime}=e^{X_{i}}$ as the input and output of DEA. The positive results obtained are used as the input and output of DEA. The comprehensive efficiency analysis of the sustainable development, the sustainable development ability $\theta$ value, and the results of the sustainable development analysis of Jiaozuo are shown in Tables 9 and 10 and in Figure 3.

From Tables 9 and 10 and Figure 3 and above, it can be observed that DEA was effective in 2000, 2004, 2006, 2010, and 2012, showing that technology and scale during these five years were effective. The comprehensive efficiency is 1 , which indicated that scale benefit did not change. The input and output were reasonable, and the development produced high efficiency and stability. The results showed DEA was weakly effective in 1999, 2001, 2002, 2003, and 2013, which suggested that only technology was effective and scale was ineffective.

(2) Analysis on the Redundant Input and Insufficient Output. DEA was ineffective in 2005, 2007, 2008, 2009, and 2011, which showed that technology and scale during these five years were not effective and sustainable development was not on track. In Table 11, it can be observed that the input of human resource and power was excessive during these five years, which showed that there was a certain energy-saving

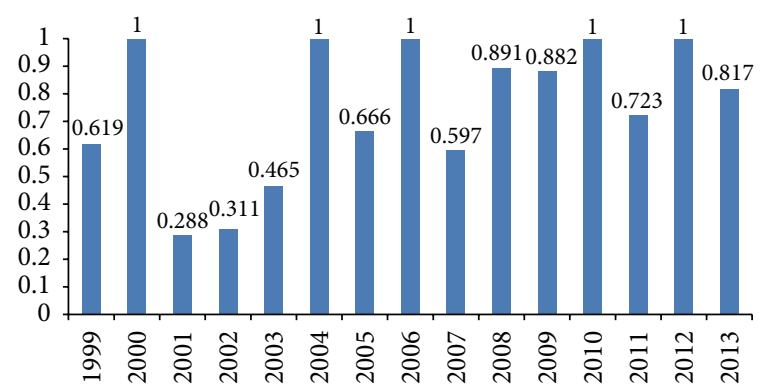

FIgURE 3: Sustainable development ability $\theta$ value of Jiaozuo.

potential in Jiaozuo and that the sustainable development of Jiaozuo could increase as well.

\section{Conclusions and Implications}

Utilizing the DEA model and data from 1999 to 2013, this paper evaluates the sustainable development of Jiaozuo and the effectiveness of technology and scale. Additionally, this paper analyzes the redundant input and insufficient output in the five years of ineffective DEA. For Jiaozuo, this paper puts forward the following recommendations of how to achieve sustainable economic, societal, and environmental development.

(1) Figure 3 shows that sustainable development in Jiaozuo appears to be in fluctuation, which highlights that development after the resource-based energy shift is not sustainable. Thus, the key is to continue the revitalization of Jiaozuo's economy. Over the next few decades, Jiaozuo should continue to vigorously develop tourism, moderately develop industry, and build the characteristics that facilitate tourism in resource-based cities to enable the economy to realize sustainable and rapid development. The transformation of Jiaozuo shows that it is not suited to reindustrialization.

(2) During the years of ineffective DEA, the input of human resource and power was excessive, while the output was insufficient. Therefore, Jiaozuo needs to adjust the input during future development, avoiding unsustainable development of redundant input and insufficient output.

(3) In the future, Jiaozuo should improve the level of scale and technical efficiency, increase investment in scientific research, introduce foreign capital and technology, promote technological progress, and improve the level of technological innovation to improve the level of sustainable development.

\section{Conflict of Interests}

The authors declare no conflict of interests. 
TABLE 10: Evaluation results of sustainable development of Jiaozuo.

\begin{tabular}{llllccc}
\hline Year & Crste & Vrste & Scale & RE & SE & TE \\
\hline 1999 & 0.619 & 1.000 & 0.619 & WDEAE & IRS & E \\
2000 & 1.000 & 1.000 & 1.000 & DEAE & NC & E \\
2001 & 0.288 & 1.000 & 0.288 & WDEAE & IRS & E \\
2002 & 0.311 & 1.000 & 0.311 & WDEAE & IRS & E \\
2003 & 0.465 & 1.000 & 0.465 & WDEAE & IRS & E \\
2004 & 1.000 & 1.000 & 1.000 & DEAE & NC & OTT \\
2005 & 0.666 & 0.973 & 0.684 & DEAI & IRS & OTT \\
2006 & 1.000 & 1.000 & 1.000 & DEAE & NC & E \\
2007 & 0.597 & 0.901 & 0.663 & DEAI & IRS & OTT \\
2008 & 0.891 & 0.969 & 0.919 & DEAI & IRS & I \\
2009 & 0.882 & 0.968 & 0.911 & DEAI & DRS & OTT \\
2010 & 1.000 & 1.000 & 1.000 & DEAE & NC & I \\
2011 & 0.723 & 0.809 & 0.895 & DEAI & IRS & OTT \\
2012 & 1.000 & 1.000 & 1.000 & DEAE & NC & I \\
2013 & 0.817 & 1.000 & 0.817 & DDEAE & OTT \\
\hline
\end{tabular}

Note: relative efficiency (RE), scale effectiveness (SE), technology effectiveness (TE), sustainable development track (SDT), weak DEA efficiency (WDEAE), DEA efficiency (DEAE), DEA ineffective (DEAI), increasing scale (IRS), decreasing scale (DRS), no change (NC), effectiveness (E), ineffectiveness (I), on the track (OTT), and inferior to track (ITT).

TABLE 11: Analysis on the redundant input and insufficient output.

\begin{tabular}{cccccc}
\hline \multirow{2}{*}{ Year } & \multicolumn{2}{c}{ Redundant input } & \multicolumn{3}{c}{ Insufficient output } \\
& $X 1$ & $X 2$ & $Y 1$ & $Y 2$ & $Y 3$ \\
\hline 2005 & -0.021 & -0.013 & 0.439 & 1.786 & 0.685 \\
2007 & -0.236 & -0.043 & 5.042 & 1.832 & 0.738 \\
2008 & -0.076 & -0.013 & 4.488 & 1.494 & 0 \\
2009 & -0.153 & -0.019 & 2.659 & 2.004 & 0 \\
2011 & -1.501 & -0.116 & 0 & 3.94 & 0.866 \\
\hline
\end{tabular}

\section{Authors' Contribution}

Li Li and Yalin Lei designed the research and methodology; Dongyang Pan and Li Li collected and compiled all the data and literature; Li Li and Chunyan Si finished the experiment and calculation; Yalin Lei and Li Li analyzed the results and put forward the policies; Yalin Lei and $\mathrm{Li} \mathrm{Li}$ revised and approved the paper; Yalin Lei will be responsible for the future questions from readers as the corresponding author.

\section{Acknowledgments}

The authors express their sincere thanks for the support from the National Natural Science Foundation of China under Grant no. 71173200 and the support from the Development and Research Center of China Geological Survey under Grant nos. 1212011220302 and 12120114056601, and Key Laboratory of Carrying Capacity Assessment for Resource and Environment, Ministry of Land and Resources (Chinese Academy of Land and Resource Economics, China University of Geosciences Beijing) under Grant no. CCA2015.08.

\section{References}

[1] The Central People's Government of the People's Republic of China, "Notice on the sustainable development plan of the national resource-based cities issued by the State Council (20132020)," 2013, http://www.gov.cn/zwgk/2013-12/03/content_ 2540070.htm.

[2] Xinhuanet, Full text of Jiang Zemin's Report at 16th Party Congress, 2012, http://news.xinhuanet.com/ziliao/2002-11/17/ content_693542.htm.

[3] The Central People's Government of the People's Republic of China, "Opinions on promoting the sustainable development of resources-based cities of the State Council," http://www.gov.cn/zwgk/2007-12/24/content_841978.htm.

[4] The Central People's Government of the People's Republic of China, "Research on the sustainable development of the first 12 resource-exhausted cities in China," 2008, http://www.gov.cn/ztzl/2008-09/19/content_1100369.htm.

[5] Z. C. Yang, "The theory review of domestic and foreign research on the transition of resource-based cities," Shanghai Economic Research, vol. 6, pp. 66-73, 2010.

[6] M. R. Betz, M. D. Partridge, M. Farren et al., "Coal mining, economic development, and the natural resources curse," Energy Economics, vol. 50, pp. 105-116, 2015.

[7] P. Andrews and J. Playfoot, "Case study 4-Houston: building on success: how community colleges in Houston are addressing workforce development within the world's most successful energy sector," in Education and Training for the Oil and Gas Industry, pp. 53-69, Elsevier, 2015.

[8] J. Monstadt and A. Wolff, "Energy transition or incremental change? Green policy agendas and the adaptability of the urban energy regime in Los Angeles," Energy Policy, vol. 78, pp. 213224, 2015.

[9] A. Thiel, "Constitutional state structure and scalar re-organization of natural resource governance: the transformation of polycentric water governance in Spain, Portugal and Germany," Land Use Policy, vol. 45, pp. 176-188, 2015.

[10] P. Ulrich, J. Dieter, K. Franz, and S. Jürgen, "Rural community studies in the federal republic of Germany," Rural Community Studies in Europe, pp. 37-129, 1982.

[11] G. Halseth, L. Ryser, S. Markey, and A. Martin, "Emergence, transition, and continuity: resource commodity production 
pathways in northeastern British Columbia, Canada," Journal of Rural Studies, vol. 36, pp. 350-361, 2014.

[12] S. Kinnear and I. Ogden, "Planning the innovation agenda for sustainable development in resource regions: a central Queensland case study," Resources Policy, vol. 39, no. 1, pp. 4253, 2014.

[13] B. Marsh, "Continuity and decline in the anthracite towns of Pennsylvania," Annals of the Association of American Geographers, vol. 77, no. 3, pp. 337-352, 1987.

[14] R. L. Warren, The Community in America, Rand McNally College Publishing, Chicago, Ill, USA, 1st edition, 1963.

[15] J. H. Bradbury, "Living with boom and cycles: new towns on the resource frontier in Canada," Resource Communities, pp. 3-19, 1988.

[16] C. O'faischeallaigh, "Economic base and employment structure in northern territory mining towns," in Resource Communities: Settlement and Workforce Issues, pp. 221-236, CSIRO, Dickson, Australia, 1988.

[17] C. Collados and T. P. Duane, "Natural capital and quality of life: a model for evaluating the sustainability of alternative regional development paths," Ecological Economics, vol. 30, no. 3, pp. 441-460, 1999.

[18] P. Cheshire, "Explaining the recent performance of the European Community's major urban regions," Urban Studies, vol. 27, no. 3, pp. 311-333, 1990.

[19] W. Y. Li, "Industrial development and urban planning of coalbased cities," The Geographical Journal, vol. 1, pp. 23-26, 1978.

[20] C. Y. Wu and Y. Ye, "On the industrial transformation of resource-based cities," Journal of Dalian University of Technology (Social Science Edition), vol. 3, pp. 6-9, 2000.

[21] Y. G. Liu, "Research on the resource-based structure transformation of in Daqing," Economic Geography, vol. 20, pp. 26-29, 2000.

[22] S. C. Dong, Z. H. Li, B. Li et al., "The problem and strategy of economic transformation of resource-based cities in China," China Population Resources and Environment, vol. 17, pp. 12-17, 2007.

[23] Y. X. Song and Q. Man, "Study on economic structure transformation of resource-based cities in Northeast China," World Geography Research, vol. 27, pp. 91-97, 2008.

[24] W. Li and T. Zhang, "Research on the circular economy evaluation index system in resource based city," Science of Science and Management of S. \& T., vol. 8, p. 18, 2005.

[25] H. J. Zhang and Z. G. Gao, "Problems of industry transformation based on sustainable development ability of resourcebased city-a case study on karamay City, Xinjiang," Arid Land Geography, vol. 3, pp. 409-413, 2005.

[26] H. Li, R. Long, and H. Chen, "Economic transition policies in Chinese resource-based cities: an overview of government efforts," Energy Policy, vol. 55, pp. 251-260, 2013.

[27] F. Dong, R. Long, H. Chen, X. Li, and X. Liu, "The convergence test of transformation performance of resource cities in China considering undesirable output," Mathematical and Computer Modelling, vol. 58, no. 5-6, pp. 948-955, 2013.

[28] G. Hong and Z. Kai, "Research on sustainable development of resource-based small industrial and mining cities-a case study of Yangquanqu town," Procedia Engineering, vol. 21, pp. 633640, 2011.

[29] Q. Z. Bu, Jiaozuo Yearbook from 2000 to 2014, Zhongzhou Ancient Books Publishing House, Henan, China, 1st edition, 2000-2014.
[30] J. Xu, "Comprehensive evaluation and analysis on the sustainable development in Jiaozuo," Regional Research and Development, vol. 23, pp. 30-33, 2004.

[31] X. H. Feng, "Analysis on the sustainable development of tourism industry in China's resource-based cities-taking Jiaozuo city as an example," Resource Development \& Market, vol. 25, pp. 460462, 2009.

[32] J. J. Chen, X. Q. Li, and L. L. Liu, "Exploration and practices on sustainable development of coal resource type city-taking Jiaozuo city as example," China Mining Magazine, vol. 17, pp. 4345, 2008.

[33] Y. G. Chang, L. X. Fan, and Q. Song, "Study on the sustainable development ability of Jiaozuo based on ecological carrying capacity," Research of Soil and Water Conservation, vol. 15, pp. 180-185, 2008.

[34] I. Moffatt, "Ecological footprints and sustainable development," Ecological Economics, vol. 32, no. 3, pp. 359-362, 2000.

[35] W. Rees and M. Wackernagel, "Urban ecological footprints: why cities cannot be sustainable-and why they are a key to sustainability," in Urban Ecology, pp. 537-555, Springer, New York, NY, USA, 2008.

[36] The United Nations Development Programme, Human Development Report 1990, Oxford University Press, Oxford, UK, 1990.

[37] B. Giddings, B. Hopwood, and G. O’Brien, "Environment, economy and society: fitting them together into sustainable development," Sustainable Development, vol. 10, no. 4, pp. 187196, 2002.

[38] J. Li, "Index system model of estimation on the sustainable development of resources exhausted cities," Resources \& Industries, vol. 7, pp. 4-8, 2005.

[39] W. J. Wu and X. S. Cheng, "Study on the evaluation index system construction of the sustainable development of resource-based cities," Coal Economic Research, vol. 2, pp. 18-19, 2009.

[40] X. Y. Shi, "Research on the evaluation index system construction in the resource-based cities transformation," Business Economics, vol. 19, pp. 85-86, 2012.

[41] X. Xu, "Research on the evaluation index system of the green development in the resource-based cities in China," Chinese and Foreign Entrepreneurs, vol. 10, pp. 7-10, 2014.

[42] J. Ravetz, "Integrated assessment for sustainability appraisal in cities and regions," Environmental Impact Assessment Review, vol. 20, no. 1, pp. 31-64, 2000.

[43] E. K. Zavadskas and J. Antucheviciene, "Development of an indicator model and ranking of sustainable revitalization alternatives of derelict property: a Lithuanian case study," Sustainable Development, vol. 14, no. 5, pp. 287-299, 2006.

[44] C. B. Hao and S. J. Dai, "Evaluation of sustainable development of coal-based cities via entropy," Resources \& Industries, vol. 10, no. 3, pp. 1-5, 2008.

[45] W. Li and J. Li, "A case study on Shanxi province: transformation efficiency evaluation of resources-based cities on DEA," Resources \& Industries, vol. 16, pp. 7-12, 2014.

[46] M. L. Wen and H. S. Li, "Fuzzy Data Envelopment Analysis (DEA): model and ranking method," Journal of Computational and Applied Mathematics, vol. 223, no. 2, pp. 872-878, 2009.

[47] M. L. Wen, C. L. You, and R. Kang, "A new ranking method to fuzzy data envelopment analysis," Computers \& Mathematics with Applications, vol. 59, no. 11, pp. 3398-3404, 2010.

[48] S. H. R. Hajiagha, H. A. Mahdiraji, E. K. Zavadskas, and S. S. Hashemi, "A fuzzy data envelopment analysis approach based on parametric programming," International Journal of 
Computers, Communications \& Control, vol. 8, no. 4, pp. 594607, 2013.

[49] J. S. Liu, L. Y. Lu, and W. M. Lu, "Research fronts in data envelopment analysis," Omega, vol. 58, pp. 33-45, 2016.

[50] Y. W. Niu, Operational Research, Xi'an Jiaotong University Press, Shanghai, China, 3rd edition, 2013.

[51] R. D. Banker, A. Charnes, and W. W. Cooper, "Some models for estimating technical and scale inefficiencies in data envelopment analysis," Management Science, vol. 30, no. 9, pp. 10781092, 1984.

[52] A. Charnes, W. W. Cooper, B. Golany, L. Seiford, and J. Stutz, "Foundations of data envelopment analysis for ParetoKoopmans efficient empirical production functions," Journal of Econometrics, vol. 30, no. 1-2, pp. 91-107, 1985.

[53] R. Färe and S. Grosskopf, "A nonparametric cost approach to scale efficiency," The Scandinavian Journal of Economics, vol. 87, no. 4, pp. 594-604, 1985.

[54] A. Charnes, W. W. Cooper, and Q. L. Wei, "A semi-infinite multicriteria programming approach to data envelopment analysis with infinitely many decision making units," Center for Cybernetic Studies Report CCS 511, 1986.

[55] A. Charnes, W. W. Cooper, Q. L. Wei, and Z. M. Huang, "Cone ratio data envelopment analysis and multi-objective programming," International Journal of Systems Science, vol. 20, no. 7, pp. 1099-1118, 1989.

[56] The State Statistical Bureau, China City Statistical Yearbook 2000 to 2014, China Statistics Press, Beijing, China, 1st edition, 20002014. 


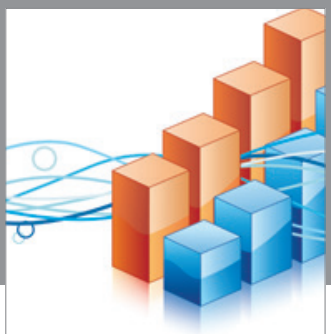

Advances in

Operations Research

vatem alat4

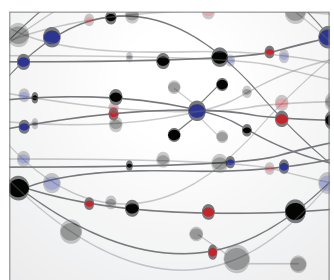

\section{The Scientific} World Journal
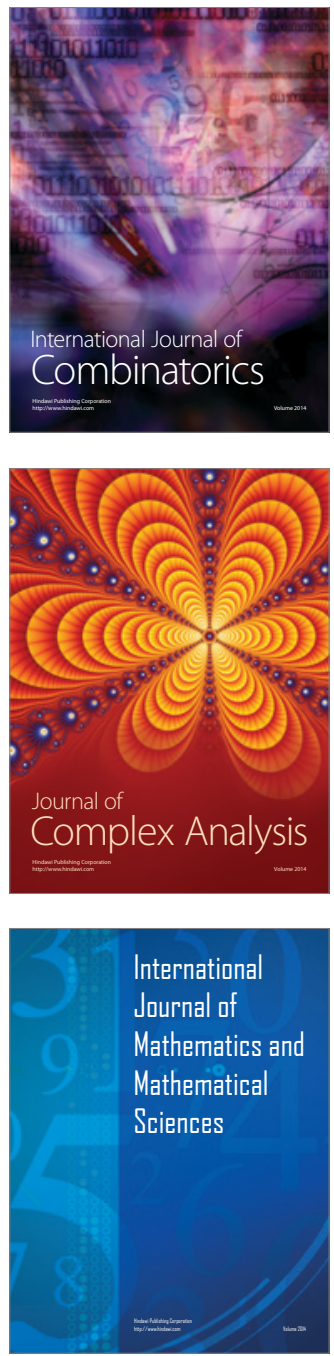
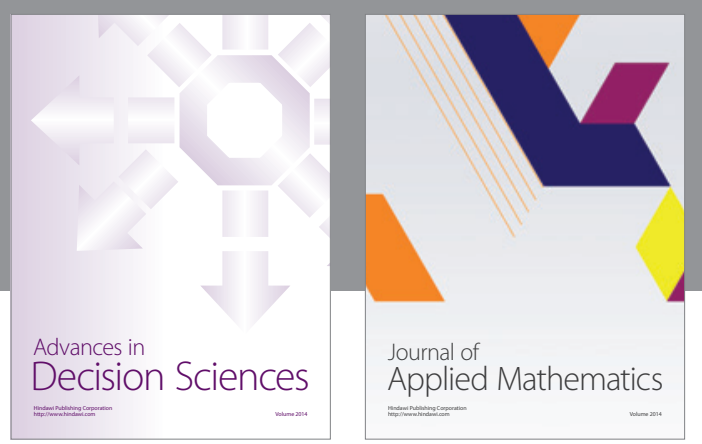

Algebra

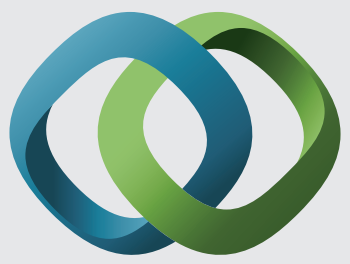

\section{Hindawi}

Submit your manuscripts at

http://www.hindawi.com
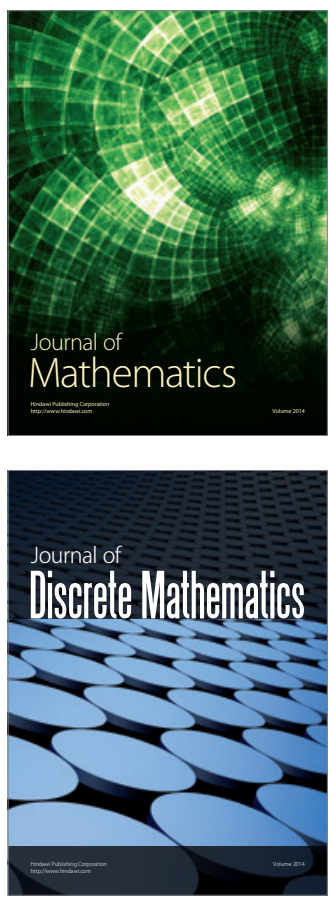

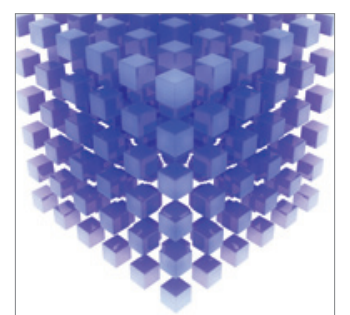

Mathematical Problems in Engineering
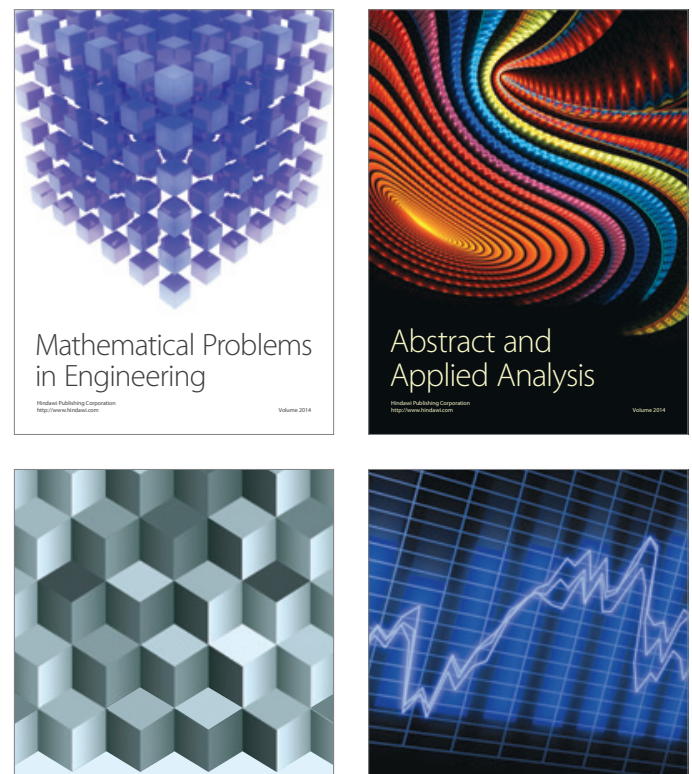

Journal of

Function Spaces

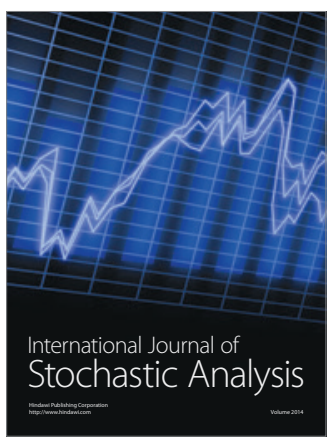

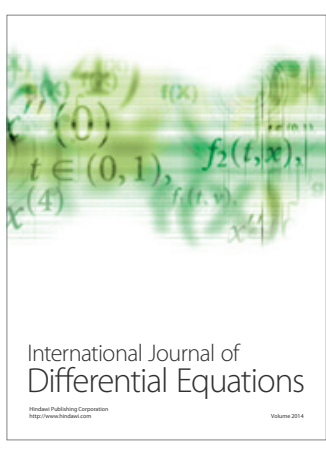
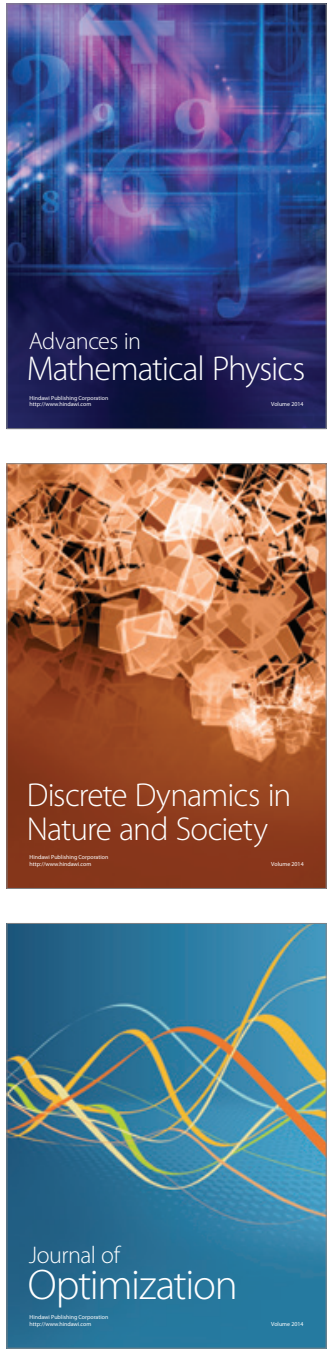